\title{
FORMAÇÃO DE PREÇO NA ECONOMIA POPULAR SOLIDÁRIA: UM DIÁLOGO CONTROVERSO COM A ECONOMIA CONVENCIONAL
}

\author{
SILVA, Sara de Souza $^{1}$ \\ Graduanda em Ciências Econômicas, bolsista de Iniciação Científica CNPq e membro da Incubadora \\ de Iniciativas da Economia Popular e Solidária da Universidade Estadual de Feira de \\ Santana/Bahia/Brasil. sarah.silva58@hotmail.com
}

LIMA, José Raimundo Oliveira ${ }^{2}$

Professor do Curso de Ciências Econômicas e Coordenador do Programa de Extensão e Pesquisa Incubadora de Iniciativas da Economia Popular e Solidária da Universidade Estadual de Feira de

Santana/Bahia/Brasil. joseraimundouefs@hotmail.com

PALAVRAS-CHAVE: Finanças solidária- comercio justo- outra economia.

\section{INTRODUÇÃO}

A economia convencional preocupa-se em responder de que maneira alocar os recursos escassos que estão diretamente ligados ao crescimento econômico, ainda que se justifique em nome do bem-estar-social. Entretanto, a definição econômica caracteriza a realidade de forma racional e utilitária de seus meios de produção e comportamento do consumidor, levando-se em consideração entre os fatores que influenciam a demanda a ênfase apenas na renda. Enquanto o modo de produção capitalista espera retornos (lucros) que remunera continuamente o capital, explorando o trabalhador, na economia popular e solidária esses retornos que são denominadas sobras, pois é o valor remanescente que fica à disposição da iniciativa, e que remunera o trabalhador valorizando sua força de trabalho.

A economia popular e solidária contribui para a construção do comercio justo e consequentemente para a formação do preço, pois não há porque esconder a centralidade do trabalho na reprodução ampliada da vida. Esse modo de comercialização segue a lógica de relação de proximidade visando a compra e a venda direta de produtos. Sendo assim o produtor sabe para quem vende, como vende e, a que preço irá vender pois interessa-se em remunerar justamente a sua força de trabalho, cuja principal necessidade é também cobrir os custos de produção sem visar o lucro exacerbado na lógica do capital. Sendo assim o produtor conhecendo as necessidades do consumidor e conhecendo os custos de ponta a ponta tem a possibilidade de comercializar um produto de qualidade e obter custobenefício com preço justo e transparente remuneração dos fatores envolvidos, especialmente, o trabalho. Neste contexto, ao logo da pesquisa problematizamos como si dar a formação de preço em uma relação de produção entre duas possiblidades econômicas: a economia de mercado e a economia popular e solidária(produção associada). Com efeito, definimos como objetivo principal discutir a formação de preço na economia popular solidária considerando um diálogo controverso entre a economia 
convencional e uma outra economia, a economia popular e solidária.

\section{METODOLOGIA}

A metodologia na nossa perspectiva é o caminho que construímos no esclarecimento sobre a pesquisa ou estudo que elaboramos juntos pesquisador e pesquisado, assumindo uma posição politica sobre seus resultados. Segundo Thiollent (2011, p.9) "não existe neutralidade na pesquisa social em geral, e tampouco na pesquisaação". Sendo assim a pesquisa convencional ou positivista se assim preferir defini-la tem contribuído para a desmistificação das possíveis respostas para as perguntas do campo da investigação científica.

${ }^{1}$ Graduanda em Ciências Econômicas pela Universidade Estadual de Feira de Santana e Bolsista de Iniciação Científica CNPq da Incubadora de Iniciativa de Economia Popular e Solidária da Universidade Estadual de Feira de Santana/Bahia/Brasil.

2 Professor Doutor do Curso de Ciências Econômicas e Coordenador do Programa de Extensão e Pesquisa Incubadora de Iniciativas da Economia Popular e Solidária da Universidade Estadual de Feira de Santana/Bahia/Brasil.

Com efeito, a saber, realizou-se atividades diagnósticas para identificar as potencialidades do grupo. Foram também realizadas atividades de apresentação do planejamento financeiro de construção dos instrumentos participativos que teve como objetivo expor a proposta das rodadas de oficinas com ênfase em organizar o controle financeiro do grupo "Delicia das Formigas" para fim de viabilizar com mais eficácia a autogestão do grupo. Quanto às oficinas especificas de planejamento financeiro e em cada foi sendo trabalhados formulários baseados na realidade de gestão vivenciada pela cantina. E assim, apresentada a proposta de formação e a planilha de compras, bem como o formulário de despesas fixas.

Em virtude da proposta apresentada se deu a seguinte formação a qual tratou da discussão do processo de execução das compras. Desta forma, definimos como funcionaria o acompanhamento das compras e também foi feita a montagem da lista de acordo com as necessidades do grupo. Com o processo de gestão de compras o grupo demandou oficinas de formação de preço, pois estavam com dificuldades em ajustar os preços, por exemplo, do beiju que continha queijo e carne seca. As integrantes do grupo alegavam que os preços desses dois insumos estavam oscilando com bastante frequência, aí então, começamos a discutir a necessidade de fazer uma formação que as auxiliariam (as 10 mulheres) a compreender a composição dos custos. Complementarmente, foram feitas também visitas as outras cantinas com intuito de acompanhar o processo de trabalho e sua gestão. 


\section{RESULTADOS E/OU DISCUSSÃO (ou Análise e discussão dos resultados)}

A proposta apresentada neste trabalho é a formação dessas mulheres através do processo de incubação. Por essa razão a educação popular é o meio mais acessível e didático para esse tipo de pesquisa.

Segundo Freire,

Ao contrário, educar e educar-se, na prática da liberdade, é tarefa daqueles que sabem que pouco sabem - por isto sabem que sabem algo e podem assim chegar a saber mais - em diálogo com aqueles que, quase sempre, pensam que nada sabem, para que estes, transformando seu pensar que nada sabem em saber que pouco sabem, possam igualmente saber mais. (FREIRE, 1983, p. 16)

A prática de educar é permitir-se abrir para um novo universo onde tudo pode ser problematizado, tudo pode ter várias possibilidades sem um fim em si, ou um aspecto unilateral. Por isso, pretende-se articular, entre outras formas de conhecimentos, os dois saberes o popular/acadêmico para que esse leque de possibilidades possa dialogar diante das possibilidades da pesquisa.

Perante as atividades de formação realizadas cabe na presente pesquisa a discussões de cada etapa percorrida no processo de incubação. Diante disso, debatidas e comentadas os encaminhamentos e proposições do grupo e suas impressões em relação a cada etapa.

$\mathrm{Na}$ primeira atividade diagnóstica os grupos apresentaram uma dificuldade em preencher os formulários que haja vistas já estavam sendo utilizados. As primeiras observações do grupo foram em relação aos campos de preenchimento. Pontuaram que existiam campos complexos e inutilizáveis para sua realidade. Sendo assim, nosso grupo sugeriu outra atividade que as mesmas pudessem fazer mais observações e sugestões para simplificação dos formulários financeiros. E assim foi se dando a formação em processo educativo conforme discute Lima e Pita (2016).

$\mathrm{Na}$ segunda atividade foram detectados quatro eixos (compras, comercialização, produção e comercialização) que nortearam essa pesquisa. Esses quatro eixos foram construídos através de visitas e observações da gestão (autogestão) da cantina. Com efeito, na atividade de apresentação do planejamento financeiro as mulheres a cada atividade realizada davam sugestão de melhoramento de cada formulário apresentado após o seu uso, conforme sua realidade objetiva (FREIRE, 1983). Já na terceira atividade de formação percebeu-se que as mulheres tinham um pouco de dificuldade em compreender a importância da lista de compras, portanto as mesmas sugeriram atividades extras para a melhor compreensão da lista e sua importância dentro das finanças, nos possibilitando assim a articulação de conhecimentos, conforme discute Lima (2017). 
Na oficina de formação de preço podíamos perceber que elas conheciam os custos, porém, faziam de forma diferenciada ou desatenta. Muitas das vezes desconsiderando os custos com o seu próprio trabalho.

Durante e depois dessas etapas foram feitos acompanhamentos constantes onde foram observados que as mulheres, apesar de já trabalharem com aspectos alimentícios ainda tinham muitas dificuldades em relação ao atendimento, ordenamento de tarefas conforme discute Lima (2014) sobre o processo educativo de trabalho, apesar de todas fazerem tudo que fosse necessário. Ressaltamos, entretanto, que ainda existe uma grande confusão em relação a organização das tarefas, mas, os avanços são consideráveis. Apesar disso o grupo tem todas as características de trabalho associado e cooperativo com base em uma "evolução" a partir da economia popular conforme discute Kraychete (2000) em direção as fronteiras conceituais de economia solidária e economia popular e solidária conforme Singer (2002) e Lima e Pita (2016).

\section{CONSIDERAÇÕES FINAIS (ou Conclusão)}

É possível observar que a economia popular e solidária e a economia de mercado de certa forma demarcam espaços diferenciados na sociedade, mas, esse diálogo de contradições nos permitiu compreender a possiblidade e contribuições para a construção do comercio justo e, consequentemente, para a formação do preço. Esse comércio segue a lógica de relação de proximidade visando a compra e a venda direta de produtos sem negar o conhecimento integral inerente a cada processo.

Portanto, essa outra economia não se preocupa (procura conhece-los) com modelos econômicos que maximizam os lucros e a utilidade no âmbito da economia de mercado, mas, com a reciprocidade e a solidariedade em busca do desenvolvimento individual, coletivo e comunitário local.

\section{REFERÊNCIAS}

FREIRE, Paulo. Extensão ou Comunicação?. Rio de Janeiro: Editora Paz na Terra, 1983. KRAYCHETE, Gabriel; LARA, Francisco; COSTA, Beatriz. Economia dos setores populares: entre a realidade e a utopia. CAPINA, 2000.

LIMA, José Raimundo de Oliveira. Economia Popular e Solidária e Desenvolvimento

Local: uma relação estratégica. Feira de Santana-BA, Novas Edições Acadêmicas, 2017.

LIMA, José Raimundo de Oliveira e PITA, Flavia Almeida. A Incubadora de Iniciativas da Economia Popular e Solidária da UEFS e a Organização de uma Metodologia de Incubação Coletiva e Autogestionária. Feira de Santana, Shekinah, 2016.

THIOLLENT, Michel. Metodologia da pesquisa-ação. São Paulo: Cortez, 2011. 